\title{
Erratum to: The effect of omega-3 fatty-acid supplements on perioperative bleeding following posterior spinal arthrodesis
}

Dennis S. Meredith • Christopher K. Kepler • Russel C. Huang •

Brandon Hirsch • Joseph Nguyen · James C. Farmer •

Federico P. Girardi • Patrick F. O'Leary • Frank P. Cammisa

Published online: 26 June 2012

(C) Springer-Verlag 2012

\section{Erratum to: Eur Spine J}

DOI 10.1007/s00586-012-2365-1

Due to an error, the author name, Russel C. Huang, was inadvertently removed from the list of authors.

The online version of the original article can be found under doi:10.1007/s00586-012-2365-1.

D. S. Meredith $(\varangle) \cdot$ R. C. Huang $\cdot$ J. Nguyen

J. C. Farmer · F. P. Girardi · P. F. O'Leary - F. P. Cammisa

Department of Orthopedic Surgery, Hospital for Special Surgery,

535 E 70th ST, New York, NY 10021, USA

e-mail: meredithd@hss.edu

C. K. Kepler

Department of Orthopedic Surgery, Rothman Institute,

Thomas Jefferson University, Philadelphia, PA, USA

B. Hirsch

Department of Orthopedic Surgery, University of Miami,

Miami, FL, USA 